\title{
Adverse effects of subchronic exposure to cooking oil fumes on the gonads and the GPR30-mediated signaling pathway in female rats
}

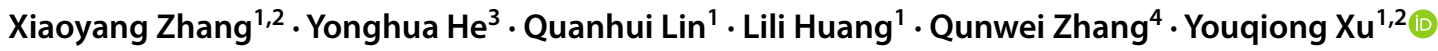

Accepted: 6 November 2019 / Published online: 11 December 2019

(c) The Author(s) 2019

\begin{abstract}
Background Cooking oil fumes (COFs) are composed of particulate matter, polycyclic aromatic hydrocarbons, volatile organic compounds, aldehydes, and ketones, and are currently a global health concern. Some agents in COFs are mutagenic and carcinogenic. However, only a few reports have addressed the hazardous effects of COF exposure on the female reproductive system. In this study, we explored the effects of subchronic exposure to COFs on female gonads in vivo and the possible involvement of the G-protein-coupled receptor 30 signaling pathway.

Methods COFs were generated by heating commercially available canola oil in an iron pot. Adult female Wistar rats at 2 months of age were exposed to COFs at $32 \mathrm{mg} / \mathrm{m}^{3}$ for $0,0.5,1,2$, or $4 \mathrm{~h} /$ day for 56 days. The estrous cycle in rats was studied twice at 7:00 a.m. and 7:00 p.m. on the 43rd treatment day until the current estrous cycle was complete. The rat body weight was measured before the experiment and at day 56 post-exposure. At the end of the experiment, rat blood was collected for gonadal hormone assay, and ovaries were collected for histology and mRNA isolation. The mRNA levels of GPR30, EGFR, STAT3, and ERK were determined by quantitative RT-PCR.

Results At a concentration of $32.21 \pm 5.11 \mathrm{mg} / \mathrm{m} 3$, COF exposure extended the estrous cycle in rats, and ovary coefficient decreased. COFs showed various effects on the sex hormone levels and follicles, depending on its exposure level. Exposure to COFs led to the changes in mRNA levels of the G-protein-coupled receptor 30 (GPR30), epidermal growth factor receptor (EGFR), signal transducer and activator of transcription 3 (STAT3), and extracellular signal-regulated kinase (ERK). Conclusion This study indicated that cooking oil fume exposure disrupted the estrous cycle, sex hormone patterns, and follicle development in female rats in a dose-dependent manner. These adverse effects of cooking oil fumes on female reproductive health were correlated with the G-protein-coupled receptor 30-mediated signaling pathway.
\end{abstract}

Keywords Cooking oil fumes $\cdot$ Female $\cdot$ Estrous cycle $\cdot$ Hormone patterns $\cdot$ Follicle development $\cdot$ G protein-coupled receptor 30

Youqiong $\mathrm{Xu}$

joancoco@163.com

1 Department of Endemic and Chronic Diseases, Fuzhou Center for Disease Control and Prevention, No. 95, Qunzhong Road, Fuzhou 350004, Fujian, People's Republic of China

2 School of Public Health, Fujian Medical University, Fuzhou, Fujian, People's Republic of China

3 School of Public Health, Guilin Medical University, Guilin, Guangxi, People's Republic of China

4 Department of Environmental and Occupational Health Sciences, University of Louisville, Louisville, KY 40292, USA

\author{
Abbreviations \\ COFs Cooking oil fumes \\ GPR30 G-protein-coupled receptor 30 \\ EGFR Epidermal growth factor receptor \\ STAT3 Signal transducer and activator of transcription 3 \\ ERK Extracellular signal-regulated kinase \\ $\mathrm{E}_{2} \quad$ Estradiol \\ $\mathrm{P}_{4} \quad$ Progesterone \\ LH Luteinizing hormone \\ FSH Follicle-stimulating hormone
}




\section{Introduction}

Cooking oil fumes (COFs) are pollutant mixtures of particulate matter, polycyclic aromatic hydrocarbons, volatile organic compounds, aldehydes, and ketones (Huang et al. 2011; Zhu et al. 2001). Our previous studies showed that different cooking oils and cooking methods contain alkanes and antioxidants (Youqiong et al. 2012). COFs are emitted from domestic and commercial cooking activities. People worldwide are exposed to COFs almost every day, and COFs are currently a global health concern because of their multiple health effects.

COFs are mutagenic and carcinogenic agents (Ke et al. 2009; Lee and Gany 2013; Wu et al. 1999). Furthermore, the complex components of COFs may exert adverse effects on the reproductive system. Benzo(a)pyrene $(\mathrm{BaP})$, a vital chemical component of COFs, has generated a substantial amount of interest, because it can disrupt gonad and endocrine function. The ovaries contain the necessary enzymes for $\mathrm{BaP}$ metabolism, fostering its reaction with reactive metabolites and disrupting normal ovarian functions (Archibong et al. 2012). Long-term, low-dose formaldehyde (one of COF components) exposure in rats substantially reduced the number and size of mature follicles, and aggravated vascular congestion and interstitial edema in their ovaries (Wang et al. 2013). Acetaldehyde (one of COF components) was reported to exert toxic effects, impairing the differentiation of granulosa cells and reducing ovulation and oocyte quality (Kawai et al. 2012).

Certain chemicals in COFs are endocrine disruptors, even at low doses, that can possibly cause vital changes in cell functions, such as non-genomic effects. Tectoridin, a major isoflavone isolated from the rhizome of Belamcanda chinensis and a known phytoestrogen, exerts its estrogenic effect mainly via the G protein-coupled receptor 30 (GPR30) and the extracellular signal-regulated kinase (ERK)-mediated rapid non-genomic estrogen signaling pathways. This endocrine disruption property of tectoridin (which is observed in other phytoestrogens, including genistein, bisphenol A, nonylphenol, and kepone) differentiates it from genistein. The phytoestrogen genistein exerts estrogenic effects via an estrogen receptor-dependent genomic pathway and a GPR30-dependent non-genomic pathway (Kang et al. 2009; Thomas and Dong 2006). G protein-coupled receptors (GPRs) bind to estrogen and participate in the rapid non-genomic signaling events that are widely observed following the stimulation of cells and tissues with estrogen. GPR30 is responsible for the receptor-mediated estrogeninduced activation of ERK, via the transactivation of the epidermal growth factor receptor (EGFR) and the release of heparan-bound epidermal growth factor (EGF) (Prossnitz and Barton 2014). The engagement of surface EGFR by cognate ligands drives the survival and proliferation of follicular dendritic cells through signaling to the nucleus, mainly via the mitogen-activated protein kinase and signal transducer and activator of transcription (STAT) pathways (Vermi et al. 2013).

Frying is a common activity, and females are more prone to COF exposure. However, only a few reports have addressed the hazardous effects of COF exposure on the female reproductive system. We studied these effects in the present study and hypothesized that the effects of COFs on the gonads are possibly related to the GPR30-mediated signaling pathway. The effects of subchronic COF exposure on female gonads in vivo were explored by analyzing changes in the estrous cycle, gonad weight, serum gonadal hormone levels, and follicle type. The possible effects of COFs on the GPR30 signaling pathway were studied by examining the mRNA levels of GPR30, EGFR, STAT3, and ERK in the ovarian tissue.

\section{Methods and materials}

\section{Generating COFs and monitoring}

Pressed canola oil was bought from a local market, and $100 \mathrm{~g}$ was poured into an iron pot (diameter $45 \mathrm{~cm}$, made of cast iron, without non-stick paint) and heated in a thermostatic oven placed atop a table at the center of a chamber (length $\times$ width $\times$ height: $1.5 \mathrm{~m} \times 1.5 \mathrm{~m} \times 3 \mathrm{~m}$ ). The temperature was controlled at $260 \pm 5^{\circ} \mathrm{C}$. A light ceiling fan was used to ensure proper circulation of the fumes in the chamber.

COFs were produced at a rate of approximately $218.4 \mathrm{mg} /$ min under the aforementioned conditions in our pilot experiments. The ventilation rate in the chamber was $6.75 \mathrm{~m}^{3} /$ $\mathrm{min}$, and the setting was designed with an exhaust fan, such that the COF level was constant at approximately $32 \mathrm{mg} / \mathrm{m}^{3}$ while the rats were treated and the exhaust was on. Generally, the concentration reached a plateau $10 \mathrm{~min}$ after heating. The dust sampler with glass fiber filter membrane and the atmospheric sampler equipped with activated carbon tube were used to collect fume from the $30 \mathrm{~cm}$ of the oil smoke generator. The discharge of the dust sampler was set to $15 \mathrm{~L} / \mathrm{min}$ and the collection time was set to $20 \mathrm{~min}$. The flow of the volatile organic compounds in the cooking oil smoke by the activated carbon tube was set to be $0.1 \mathrm{~L} / \mathrm{min}$, and the sampling time was $30 \mathrm{~min}$. After weighing, the fiber glass filters were detected by high-performance liquid chromatography (HPLC), and activated carbon tubes were used for GC-MS analysis. The COF level was estimated as the quotient of the increased weight of the filters and the sampling volume of air $\left(\mathrm{mg} / \mathrm{m}^{3}\right)$. 
With reference to the EPA Method Update TO-17 1667 of the US Environmental Protection Agency (USEPA 2009) and a related report, major COF compounds were analyzed. The chamber air was sampled once a week using a conditioned Tenax adsorption tube and pump at a flow rate of $15 \mathrm{~mL} / \mathrm{min}$ for $4 \mathrm{~h}$. During the GC-MS analysis, the sample was desorbed with an inert gas at a flow rate of $20 \mathrm{~mL} /$ min for $1 \mathrm{~min}$ at $150{ }^{\circ} \mathrm{C}$ and then at $50 \mathrm{~mL} / \mathrm{min}$ for $5 \mathrm{~min}$ at $250{ }^{\circ} \mathrm{C}$. The desorbed gas was cooled at a cold trap temperature $\left(-10^{\circ} \mathrm{C}\right)$, injected at a flow rate of $50 \mathrm{~mL} / \mathrm{min}$ into the GC-MS system (Agilent $7890 \mathrm{~A} /$ Agilent 5975C, US), and analyzed under the following operating conditions: DB5MS column $(30 \mathrm{~m} \times 320 \mu \mathrm{m} \times 1.00 \mu \mathrm{m})$; helium gas: flow rate of $1.1 \mathrm{~mL} / \mathrm{min}$; injector temperature: $250{ }^{\circ} \mathrm{C}$; temperature program: the oven temperature was held at $40^{\circ} \mathrm{C}$ for 5 min, programmed to $150{ }^{\circ} \mathrm{C}$ at $6{ }^{\circ} \mathrm{C} / \mathrm{min}$, held for another $5 \mathrm{~min}$, programmed to $250^{\circ} \mathrm{C}$ at $5^{\circ} \mathrm{C} / \mathrm{min}$, and held for $5 \mathrm{~min}$; interface temperature: $280{ }^{\circ} \mathrm{C}$; ion source temperature: $150{ }^{\circ} \mathrm{C}$; electron multiplier voltage: $1329 \mathrm{~V}$. Constant current: $1.5 \mathrm{~mL} / \mathrm{min}$; and range of ion scanning: $35-300 \mathrm{U}$, 0-4-min solvent delay. Some COF compounds were identified by comparing the retention times of the peaks with those of the reference compounds eluted under the same chromatographic condition. The peak areas of the internal standards were employed for performing quantitative tests of the specific components of COFs under the experimental exposure scenario. The other COF components were identified by comparing their spectra with those available in the National Institute of Standards and Technology (NIST) digital library (MS Search 2.0 database) and performing map analysis according to a matching factor of more than $850 \%$. Then, with reference of the designed mass and peak area of methylbenzene, an area-normalized semi-quantitative method was used for quantitative tests of those components of COFs under the experimental exposure scenario.

\section{Animal treatment}

Adult female Wistar rats at 2 months of age were randomly grouped into five polyethylene cages ( $n=10$ per treatment or control group). Rats were acclimatized to the animal care facility for 1 week prior to the initiation of experiments. They were maintained in an environmentally controlled room with natural lighting at $22{ }^{\circ} \mathrm{C}$ and $50-60 \%$ humidity. Rats had ad libitum access to commercial chow and water. Acclimated rats were weighed, and their ability to maintain regular 4-5 day estrous cycles was evaluated through daily vaginal histological examinations, which entailed using light microscopy to determine the stages of the estrous cycle (Goldman et al. 2007).

The treatment entailed subchronic COF exposure (through inhalation) at $32 \mathrm{mg} / \mathrm{m}^{3}$ for $0,0.5,1,2$, or $4 \mathrm{~h} /$ day, and this exposure lasted continuously for 56 days (Archibong et al. 2012). The rats were washed every day with detergent and warm clean water after $\mathrm{COF}$ exposure and transferred to clean cages and cells, so that they received no additional exposure. This study was approved by the animal care and use committee of our institute, and all animals were used in compliance with the National Institutes of Health guide for the care and use of laboratory animals.

\section{Estrous cycle evaluation}

The estrous cycle in rats was studied twice at 7:00 a.m. and 7:00 p.m. on the 43rd treatment day until the current estrous cycle was complete (Goldman et al. 2007).

\section{Body and gonad weight}

The individual body weights of the rats were measured using an electronic balance at the beginning and on the 56th exposure day (the final day) of the treatment. The rats were then sacrificed at the estrus stage of the first cycle within $12 \mathrm{~h}$ after treatment. The ovaries and uterus were harvested, washed in chilled $\left(4^{\circ} \mathrm{C}\right)$ isotonic saline to remove the blood on the surface, and weighed. The organ-weight-to-bodyweight ratio was computed. The time variance between the final exposure and euthanasia or tissue collection was $38.7 \pm 43.9 \mathrm{~h}$ among the rats.

\section{Gonadal hormone assay}

Blood was sampled via a heart puncture using heparinized Pasteur pipettes. Serum was harvested from each blood sample through centrifugation at $1500 \times g$ at $4{ }^{\circ} \mathrm{C}$ for $10 \mathrm{~min}$ and stored at $-20{ }^{\circ} \mathrm{C}$ until ovarian steroids [estradiol $\left(\mathrm{E}_{2}\right)$ and progesterone $\left(\mathrm{P}_{4}\right)$ ] and gonadotropins [luteinizing hormone ( $\mathrm{LH})$ and follicle-stimulating hormone (FSH)] were assayed. The hormone levels were measured using a radioimmunoassay kit (160220, Beijing North Institute of Biological Technology Co Ltd) on an automatic radioimmunity analyzer (SN-695B, Shanghai Hesuo Rihuan Photoelectric Instrument Co Ltd) according to the manufacturer's protocol. The sensitivity for $\mathrm{E}_{2}, \mathrm{P}_{4}, \mathrm{LH}$, and FSH were $15 \mathrm{pg} / \mathrm{mL}$, $0.3 \mathrm{ng} / \mathrm{mL}, 1 \mathrm{mIU} / \mathrm{mL}$, and $1 \mathrm{mIU} / \mathrm{mL}$, respectively, and the degree of accuracy was $>85 \%$ for all hormones.

\section{Follicle categorization}

Ovaries at the estrus stage were fixed in $4 \%$ paraformaldehyde at $4{ }^{\circ} \mathrm{C}$, and the slides were stored overnight before being dehydrated in ethanol at a series of concentrations, rinsed in xylene, and embedded in paraffin. From these 
slides, 5 - $\mu \mathrm{m}$-thick ovarian sections were prepared, with a distance of greater than $20 \mu \mathrm{m}$ between each section. Six representative sections from each ovary were selected and deparaffinized in xylene, dehydrated through a series of ethanol concentrations, and then stained with hematoxylin and eosin (H\&E) using standard protocols. The number and percentage of follicles at the estrous stage in each section were histologically analyzed using $10 \times$ magnification and photographed using a photomicroscope (Olympus BX50). Two independent observers, who were blinded to the treatment assignment, conducted the histopathological examination. Follicles were classified (Luo et al. 2008) as follows: primordial follicle (an oocyte surrounded by one layer of flattened granulosa cells), primary follicle (an oocyte surrounded by one layer of cuboidal granulosa cells), secondary follicle (two or three layers of cuboidal granulosa cells with no antral space), or antral follicle (more than four layers of granulosa cells with one or more independent antral spaces or with a cumulus granulosa cell layer). Antral follicles were considered atretic if they contained at least 20 apoptotic granulosa cells, disorganized granulosa cells, a degenerating oocyte, or a fragmentation of the oocyte nucleus (Juliani et al. 2008).

Pieces $\leq 0.5-1 \mathrm{~mm}$ of fresh ovary tissue samples were prefixed in a stationary liquid of $3 \%$ glutaraldehyde-paraformaldehyde and were then post-fixed with $1 \%$ osmium tetroxide and $1.5 \%$ potassium ferrocyanide (Sigma). The samples were dehydrated with increasing concentrations of alcohol and finally with acetone. The specimens were embedded in Araldite resin 618. The follicles were examined with transmission electron microscopy (Philips EM208).

\section{Quantitative RT-PCR assay for determining the mRNA levels of GPR30, EGFR, STAT3, and ERK}

Total RNA was extracted from the ovary tissue using a TRIzol reagent (Invitrogen) according to the manufacturer's instructions. The concentration and purity of the isolated total RNA was determined spectrophotometrically at $260 \mathrm{~nm}$ and $280 \mathrm{~nm}$ using a spectrophotometer (Thermo Fisher Scientific). Using primers (Invitrogen), $1 \mu \mathrm{g}$ of total RNA was reverse transcribed to cDNA using the GoScriptTM Reverse Transcription System (Progerm) according to the manufacturer's protocol. The target fragments were quantified through real-time PCR using the GoTaq ${ }^{\circledR}$ Colorless Master Mix (Invitrogen) with the cDNA template. Each sample was tested in duplicate (Zhang et al. 2012). Specific primer sets (designed by Invitrogen) are described in Table 1 . The transcript level of the housekeeping gene glyceraldehyde-3-phosphate dehydrogenase (GAPDH) was used as an internal reference gene. PCR amplification efficiencies were determined by amplifying various quantities of target cDNA for each reaction (Filippi et al. 2009). The PCR products were separated using electrophoresis. Images were captured using a charge-coupled device camera, and the relative mRNA concentrations were analyzed using Quantity One 4.6.2 (Bio-Rad) and compared with the GAPDH level, which served as a Kong et al. (2011).

\section{Statistical analysis}

The normal distribution of COF concentrations was evaluated using the one-sample KS test. All differences in laboratory measurements among the dose groups were analyzed using one-way analysis of variance (ANOVA). Data are expressed as the mean and standard deviation $\left(\bar{x}_{ \pm} \mathrm{s}\right)$.

Table 1 Primers for real-time PCR

\begin{tabular}{|c|c|c|c|c|}
\hline Gene & Forward primer $\left(5^{\prime} \rightarrow 3^{\prime}\right)$ & Reverse primer $\left(5^{\prime} \rightarrow 3^{\prime}\right)$ & $\begin{array}{l}\text { Product } \\
\text { size (bp) }\end{array}$ & PCR cycles \\
\hline GPR30 & ATCGGCCTGTTCCT CTCGT & CATCTTCTCGCG GAAGCTGAT & 105 & $\begin{array}{l}95^{\circ} \mathrm{C} 2 \mathrm{~min},\left(95^{\circ} \mathrm{C} 30 \mathrm{~s}, 57^{\circ} \mathrm{C} 30 \mathrm{~s},\right. \\
\left.72^{\circ} \mathrm{C} 30 \mathrm{~s}\right)^{*} 30 \text { cycles, } 72{ }^{\circ} \mathrm{C} \\
5 \mathrm{~min}, 4{ }^{\circ} \mathrm{C} \text { Pause }\end{array}$ \\
\hline EGFR & GAGAAAGAATA CCATGCAGAAGG & TCTGGTGGGTAT AGATTCTGTGT & 88 & $\begin{array}{l}95^{\circ} \mathrm{C} 2 \min ,\left(95^{\circ} \mathrm{C} 30 \mathrm{~s}, 54{ }^{\circ} \mathrm{C}\right. \\
\left.30 \mathrm{~s}, 72{ }^{\circ} \mathrm{C} 30 \mathrm{~s}\right)^{*} 40 \text { cycles, } 72{ }^{\circ} \mathrm{C} \\
5 \mathrm{~min}, 4^{\circ} \mathrm{C} \text { Pause }\end{array}$ \\
\hline STAT3 & TCCATCAGCTCT ACAGTGACAGC & TCCCAGGAGATT ATGAAACACC & 134 & $\begin{array}{l}95^{\circ} \mathrm{C} 2 \min ,\left(95^{\circ} \mathrm{C} 30 \mathrm{~s}, 54{ }^{\circ} \mathrm{C}\right. \\
\left.30 \mathrm{~s}, 72^{\circ} \mathrm{C} 30 \mathrm{~s}\right)^{*} 40 \text { cycles, } 72{ }^{\circ} \mathrm{C} \\
5 \mathrm{~min}, 4{ }^{\circ} \mathrm{C} \text { Pause }\end{array}$ \\
\hline ERK & AAAATTGAGCAG GTGATCGG & TCACAGGTGTGC TCTTGGTC & 223 & $\begin{array}{l}95^{\circ} \mathrm{C} 2 \mathrm{~min},\left(95^{\circ} \mathrm{C} 30 \mathrm{~s}, 56{ }^{\circ} \mathrm{C}\right. \\
\left.30 \mathrm{~s}, 72^{\circ} \mathrm{C} 30 \mathrm{~s}\right)^{*} 30 \text { cycles, } 72{ }^{\circ} \mathrm{C} \\
5 \mathrm{~min}, 4{ }^{\circ} \mathrm{C} \text { Pause }\end{array}$ \\
\hline GAPDH & AAAATTGAGCAG GTGATCGG & CCTGCTTCACCA ССТTCTTG & 113 & $\begin{array}{l}95^{\circ} \mathrm{C} 2 \min ,\left(95^{\circ} \mathrm{C} 30 \mathrm{~s}, 55^{\circ} \mathrm{C}\right. \\
\left.30 \mathrm{~s}, 72^{\circ} \mathrm{C} 30 \mathrm{~s}\right) * 35 \text { cycles, } 72{ }^{\circ} \mathrm{C} \\
5 \mathrm{~min}, 4^{\circ} \mathrm{C} \text { Pause }\end{array}$ \\
\hline
\end{tabular}


Table 2 Some chemical concentrations of COFs in the experimental exposure scenario analyzed by HPLC and GC-MS

\begin{tabular}{lcll}
\hline COFs chemicals & $\begin{array}{l}\text { Minimum } \\
\left(\mu \mathrm{g} / \mathrm{m}^{3}\right)\end{array}$ & $\begin{array}{l}\text { Maximum } \\
\left(\mu \mathrm{g} / \mathrm{m}^{3}\right)\end{array}$ & $\begin{array}{l}\text { Mean } \\
\left(\mu \mathrm{g} / \mathrm{m}^{3}\right)\end{array}$ \\
\hline Dipropylmethane & 151.6 & 257.3 & $219.3 \pm 67.1$ \\
Hexanal & 120.2 & 203.7 & $194.2 \pm 35.7$ \\
Amyl hydride & 120.2 & 203.7 & $124.9 \pm 62.2$ \\
Octane & 115.0 & 194.8 & $168.2 \pm 56.2$ \\
2-Heptene aldehyde & 59.0 & 99.2 & $110.5 \pm 37.6$ \\
1-pentanol & 53.8 & 90.3 & $108.4 \pm 20.2$ \\
Acraldehyde & 46.7 & 78.3 & $81.9 \pm 31.3$ \\
Phenylethylene & 26.7 & 44.1 & $34.5 \pm 25.3$ \\
Xylene & 26.5 & 43.7 & $33.7 \pm 17.2$ \\
Formaldehyde & 16.4 & 46.4 & $22.3 \pm 10.2$ \\
Propylgallate & 17.7 & 28.7 & $21.5 \pm 9.5$ \\
Benzopyrene & 6.3 & 17.7 & $9.7 \pm 3.6$ \\
Butylated hydroxytoluene & 1.6 & 2.5 & $1.9 \pm 0.7$ \\
Tertiary butylhydroquinone & 1.3 & 2.1 & $1.5 \pm 0.7$ \\
\hline
\end{tabular}

Values represent mean $\pm \mathrm{SD}(n=8)$

\section{Results}

\section{Airborne COFs in the treatment chamber}

There were 56 airborne COF samples used in the treatment for the concentration analysis. The COF concentrations were normally distributed. The arithmetic mean was $32.21 \mathrm{mg} / \mathrm{m}^{3}$ with a standard deviation of $5.11 \mathrm{mg} / \mathrm{m}^{3}$. The GC-MS and HPLC analysis results (Table 2) indicated that aldehydes and alkyls were the main chemicals in the COFs. BaP was detectable at a high concentration under the experimental conditions. Moreover, antioxidant additives, such as butylated hydroxytoluene and tertiary butylhydroquinone, were found in the COFs.

\section{Effects of COFs on the estrous cycle}

The rats in the control group exhibited a normal 5-day estrous cycle (Table 3 ). The estrous cycles of all rats exposed to COFs were extended compared with those of the control group; however, this difference was not significant. Subchronic (43 days) exposure of rats to a high dose $(2 \mathrm{~h}$ /day) and a very high dose $(4 \mathrm{~h} /$ day $)$ of COFs significantly prolonged the metaestrous stage $(p<0.05$ and $p<0.01$, respectively).

\section{Effects of COFs on body and gonad weight}

No remarkable differences in activities, including eating or drinking, were observed in the rats of the control or treatment groups during the treatment (Table 4). No significant difference was observed in the body weight among the groups before treatment. The rats in all groups had increased

Table 3 Impact of subchronic exposure of COFs on estrous cycle (hours) of female rats measured by Yaginal Smear Test

\begin{tabular}{llllll}
\hline Group (h/day) & Proestrus & Estrus & Metestrus & Diestrus & Estrous cycle \\
\hline Control (0) & $21.6 \pm 5.1$ & $14.4 \pm 5.1$ & $15.6 \pm 5.8$ & $62.4 \pm 9.5$ & $114.0 \pm 20.4$ \\
Low (0.5) & $19.2 \pm 6.2$ & $15.6 \pm 5.8$ & $18.0 \pm 6.3$ & $69.6 \pm 14.8$ & $122.4 \pm 27.1$ \\
Medium (1.0) & $16.8 \pm 6.2$ & $16.8 \pm 6.2$ & $19.2 \pm 8.4$ & $73.2 \pm 11.9$ & $129.6 \pm 31.3$ \\
High (2.0) & $19.2 \pm 6.2$ & $19.2 \pm 8.4$ & $22.8 \pm 6.8$ & $78.0 \pm 24.9$ & $135.6 \pm 44.4^{\mathrm{a}}$ \\
Very high (4.0) & $18.0 \pm 8.5$ & $22.8 \pm 11.9$ & $26.4 \pm 5.1^{\mathrm{b}}$ & $82.8 \pm 23.6$ & $150.0 \pm 47.3^{\mathrm{b}}$ \\
\hline
\end{tabular}

Values represent mean $\pm \mathrm{SD}(n=10)$

${ }^{\mathrm{a}} p<0.05$ and ${ }^{\mathrm{b}} p<0.01$ vs. control

Table 4 Body weight and gonad coefficient of female rats after subchronic exposure of COFs for 56 days

\begin{tabular}{lllllll}
\hline Group (h/day) & $\begin{array}{l}\text { Body-weight } \\
\text { pre-treatment } \\
\end{array}$ & Body-weight gain $(\mathrm{g})$ & Uterus weight $(\mathrm{mg})$ & Uterus coefficient $^{\mathrm{A}}$ & Ovary weight $(\mathrm{mg})$ & Ovary coefficient $^{\mathrm{A}}$ \\
\hline Control (0) & $204.3 \pm 6.5$ & $26.2 \pm 2.5$ & $510 \pm 123$ & $2.21 \pm 0.56$ & $76.9 \pm 14.2$ & $33.4 \pm 6.5$ \\
Low (0.5) & $201.5 \pm 7.9$ & $32.2 \pm 6.3^{\mathrm{a}}$ & $523 \pm 123$ & $2.24 \pm 0.51$ & $90.1 \pm 12.0$ & $38.6 \pm 5.1$ \\
Medium (1.0) & $199.8 \pm 6.3$ & $30.8 \pm 5.8$ & $504 \pm 152$ & $2.18 \pm 0.68$ & $82.2 \pm 29.2$ & $35.6 \pm 1.3$ \\
High (2.0) & $203.0 \pm 4.9$ & $25.3 \pm 5.9$ & $465 \pm 100$ & $2.04 \pm 0.44$ & $71.3 \pm 25.5$ & $31.2 \pm 1.2$ \\
Very high (4.0) & $200.3 \pm 6.7$ & $21.1 \pm 6.8^{\mathrm{a}}$ & $428 \pm 123$ & $1.88 \pm 0.54$ & $60.5 \pm 18.4$ & $27.3 \pm 8.0^{\mathrm{b}}$ \\
\hline
\end{tabular}

Values represent mean $\pm \mathrm{SD}(n=10)$

${ }^{\mathrm{a}} p<0.05$ and ${ }^{\mathrm{b}} p<0.01$ vs. control

${ }^{\text {A }}$ Relative weight of organization ( $\mathrm{mg} / \mathrm{g}$ body weight, \%) 
Table 5 Levels of sex hormone of female rats after subchronic exposure of COFs for 56 days measured by radioimmunoassay

\begin{tabular}{llllll}
\hline Group (h/d) & \multicolumn{2}{l}{ Hypophyseal hormone } & & \multicolumn{2}{l}{ Ovarian hormone } \\
\cline { 2 - 3 } & FSH $(\mathrm{mIU} / \mathrm{ml})$ & $\mathrm{LH}(\mathrm{mIU} / \mathrm{ml})$ & & $\mathrm{P}_{4}(\mathrm{ng} / \mathrm{ml})$ & $\mathrm{E}_{2}(\mathrm{pg} / \mathrm{ml})$ \\
\hline Control (0) & $1.82 \pm 0.22$ & $5.94 \pm 1.80$ & & $1.97 \pm 0.51$ & $92.20 \pm 14.53$ \\
Low (0.5) & $1.87 \pm 0.36$ & $5.45 \pm 1.21$ & & $2.06 \pm 0.82$ & $99.43 \pm 32.72$ \\
Medium (1.0) & $1.77 \pm 0.24$ & $5.62 \pm 0.92$ & & $1.58 \pm 0.73$ & $95.62 \pm 26.84$ \\
High (2.0) & $1.58 \pm 0.49$ & $7.62 \pm 1.38^{\mathrm{a}}$ & & $1.44 \pm 0.48$ & $69.36 \pm 20.06^{\mathrm{a}}$ \\
Very high (4.0) & $1.99 \pm 0.48$ & $8.79 \pm 0.87^{\mathrm{b}}$ & & $1.28 \pm 0.47^{\mathrm{b}}$ & $56.71 \pm 24.50^{\mathrm{b}}$ \\
\hline
\end{tabular}

Values represent mean $\pm \operatorname{SD}(n=10)$

${ }^{\mathrm{a}} p<0.05$ and ${ }^{\mathrm{b}} p<0.01$ vs. control body weights; however, the rats in the very high COFexposed groups weighed less than those in the control group. $\mathrm{COF}$ exposure led to a significant decrease in the absolute weight of the rat ovaries in very high group $(p<0.05)$. Moreover, the relative weights of the ovaries decreased in the rats in the very high-exposure groups. COF exposure (at all doses) did not exert any effects on the uterus weight.

\section{Effects of COFs on gonadal hormones}

Irrespective of the dose, subchronic COF exposure did not affect serum FSH levels in the female rats at the estrus stage (Table 5). The LH levels of the rats increased in the high-dose and very-high-dose group, but the $\mathrm{E}_{2}$ levels of the rats decreased in the very-high-dose group $(p<0.05 / p<0.01)$. The $\mathrm{P}_{4}$ levels of the rats decreased in the very-high group $(p<0.01)$.

\section{Effects of COFs on follicle type}

To investigate whether exposure to COFs caused direct or indirect damages to the follicle structure and type in ovaries, ovarian tissues were observed under the light mirror with H\&E staining. Exposure to COFs resulted in increased follicular atresia and decreased mature follicles, while primordial/primary follicles were more observed in the control
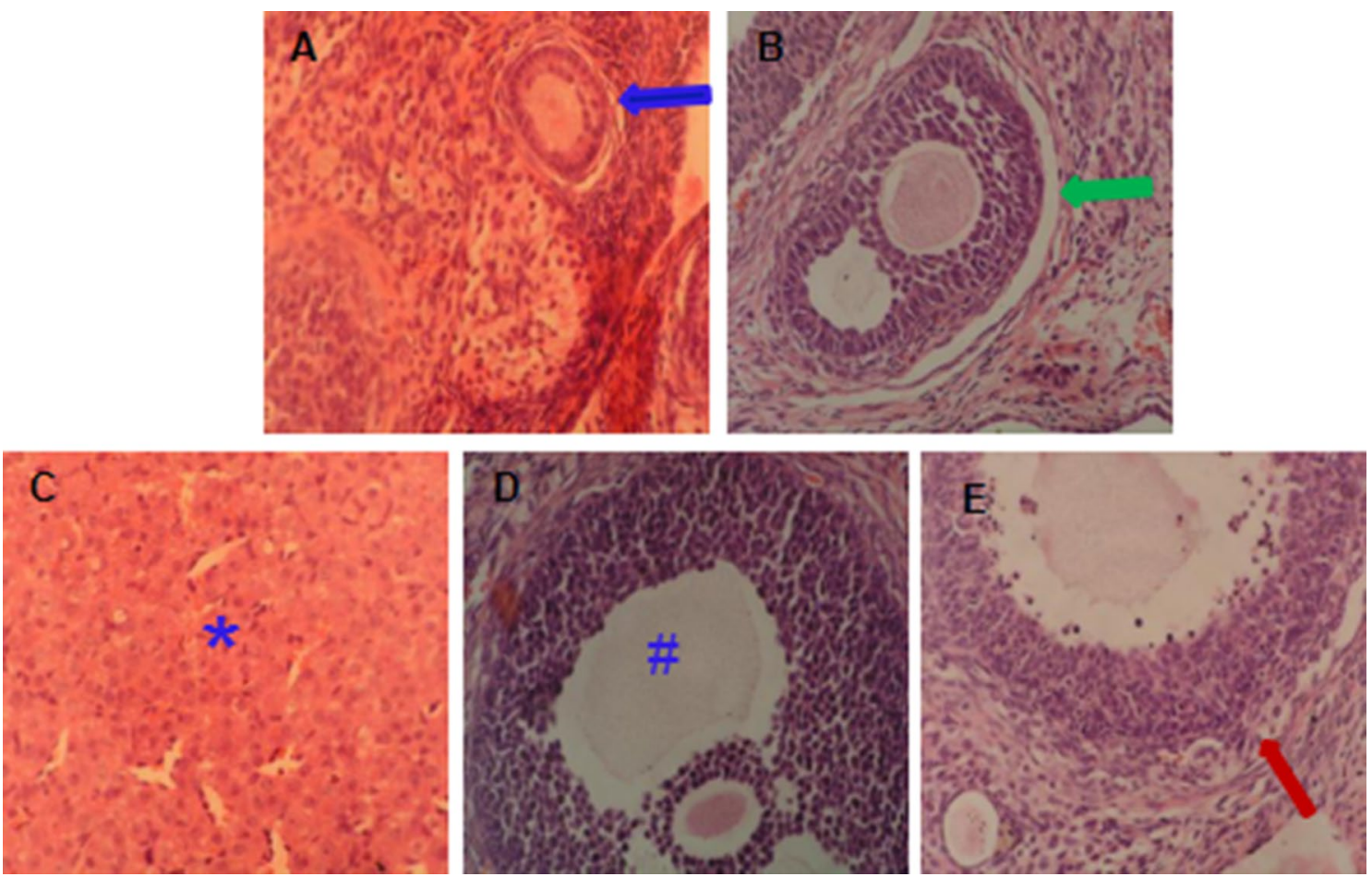

Fig. 1 Optical mirror images of ovarian. Rats were inhaled with normal air (a), low dose (b), medium dose (c), high dose (d), and very high dose (e) of COFs for 56 days. Ovarian structure was observed under the microscope with HE staining. Primordial/primary follicle is more seen in $\mathbf{a}$ (blue arrows). Secondary follicles are more seen in $\mathbf{b}$ (green arrows). Corpus lutea are more seen in $\mathbf{c}$ (the picture is corpus luteum, blue *). Graafian follicles are rarely seen in $\mathbf{d}$ (blue \#). Atretic follicle is more seen in e (red arrows). Scale bars indicate $5 \mu \mathrm{m}$ 
Table 6 The follicle types of female rats in the ovaries after subchronic exposure of COFs for 56 days measured by $\mathrm{HE}$ staining

\begin{tabular}{lllllc}
\hline Group (h/d) & $\begin{array}{l}\text { Primordial/ } \\
\text { primary fol- } \\
\text { licle }\end{array}$ & Secondary follicle & Graafian follicle & Atretic follicle & Corpus luteum \\
\hline Control (0) & $64.8 \pm 12.2$ & $21.6 \pm 4.9$ & $2.9 \pm 0.5$ & $3.1 \pm 0.6$ & $7.6 \pm 2.1$ \\
Low (0.5) & $59.2 \pm 11.2$ & $25.5 \pm 7.3^{\mathrm{a}}$ & $2.1 \pm 0.6$ & $4.4 \pm 1.9$ & $8.8 \pm 3.6$ \\
Medium (1.0) & $60.3 \pm 10.3$ & $22.6 \pm 10.1$ & $2.6 \pm 0.3$ & $5.1 \pm 1.3$ & $9.4 \pm 3.5$ \\
High (2.0) & $61.9 \pm 12.5$ & $18.7 \pm 7.0$ & $1.2 \pm 0.2^{\mathrm{a}}$ & $7.0 \pm 1.7^{\mathrm{a}}$ & $11.2 \pm 5.2$ \\
Very high (4.0) & $59.1 \pm 17.3$ & $16.3 \pm 7.2^{\mathrm{a}}$ & $0.6 \pm 0.3^{\mathrm{b}}$ & $8.5 \pm 2.2^{\mathrm{b}}$ & $15.2 \pm 4.7^{\mathrm{a}}$ \\
\hline
\end{tabular}

30 slides $=6$ slide $/$ rat $\times 5$ rats

Values represent mean $\pm \mathrm{SD}(n=30)$

${ }^{\mathrm{a}} p<0.05$ and ${ }^{\mathrm{b}} p<0.01$ vs. control
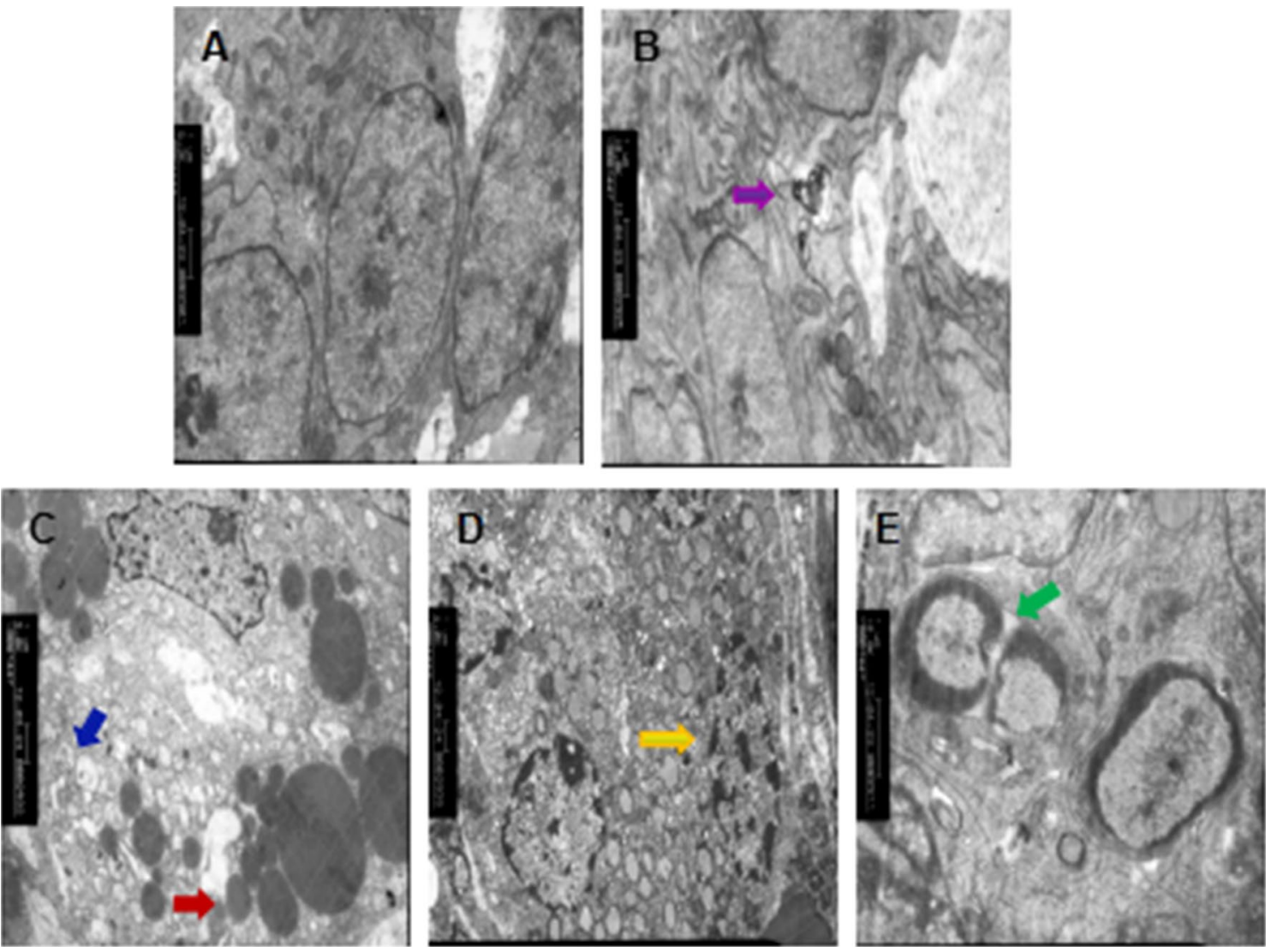

Fig. 2 TEM images of ovarian. Rats were inhaled with normal air (a), low dose (b), medium dose (c), high dose (d), and very high dose (e) of COFs for 56 days. Ovarian section was observed under TEM. Normal control ovarian ultrastructure with normal granular cells is shown in a. Chromatin accumulates in the nucleus (purple arrow in b). A

rats (Fig. 1), indicating that COFs can affect follicular development. The numbers of follicles in different grades were compared with those in ovaries. The COF treatment showed diverse effects on the percentage of follicle types. Compared to the control group, low COF exposure led to an increase in the Secondary follicle ratio during the estrous stage, but large number of lipid droplets were observed and mitochondria were swollen or even vacuolated (red arrow in $\mathbf{c}$ and yellow arrow in $\mathbf{d}$ for increased lipid droplets, and blue arrow in $\mathbf{c}$ for damaged mitochondria). Apoptosis and chromatin condensation are displayed as a crescent (green arrow in e). Scale bars indicate $75 \mathrm{~nm}$

no such change resulted from high COF exposure (Table 6). Moreover, the atretic follicles increased in number (doubled or more) after COF exposure in high-dose groups. Even the ratio of the corpus luteum slightly increased in the rats of the very-high-dose group; however, no such change was observed in any other groups. The Graafian follicle 
Fig. 3 Impact of subchronic exposure to COFs on mRNA levels of GPR30, EGFR, STAT3, and ERK $(n=10$, relative values as compared with GAPDH, $\times 10^{-2}$ ). Rats were inhaled with normal air (0), low dose (0.5), medium dose (1.0), high dose (2.0), and very high dose (4.0) of COFs for 56 days. The mRNA expression levels of GPR30, EGFR, STAT3, and ERK in rat ovaries were analyzed by real-time PCR. Values are expressed as mean $\pm \mathrm{SD}$ $(n=10) .{ }^{\mathrm{a}} p<0.05$ and ${ }^{\mathrm{b}} p<0.01$ vs. control

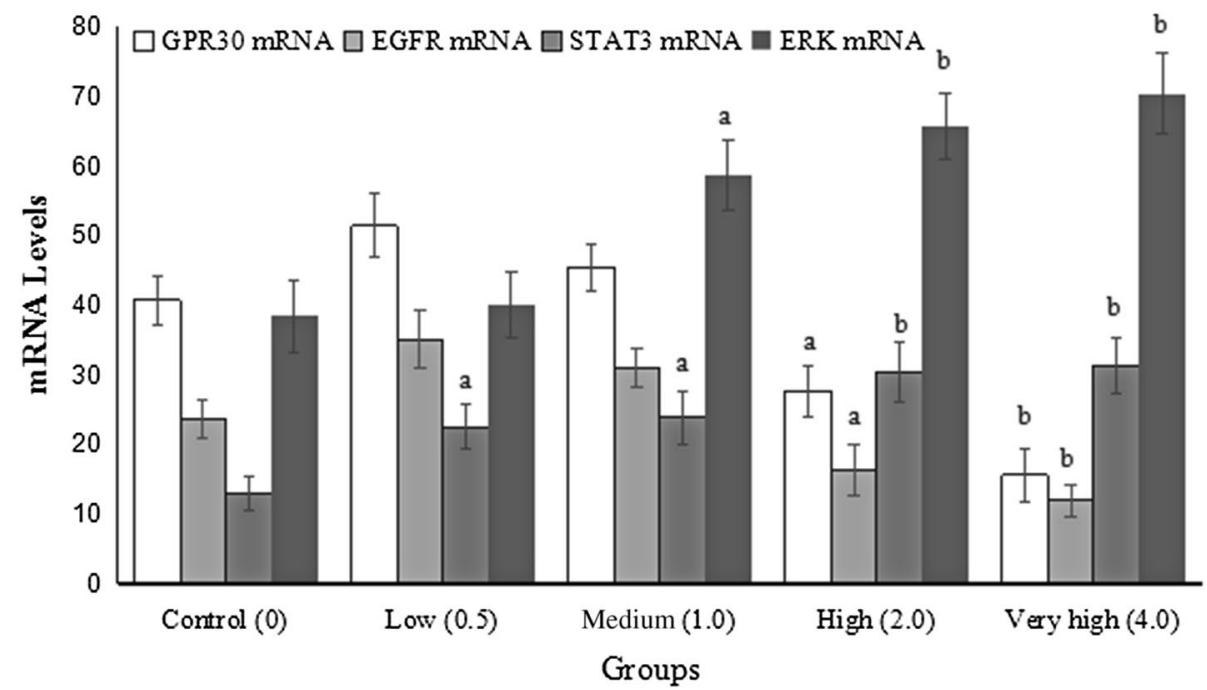

accounted for only a small portion of the follicle types, and the size decreased by approximately 1.5 -fold and 3.8 -fold in the high- and very-high-dose groups, respectively.

\section{Effects of COFs on follicular cell ultrastructure}

To investigate whether exposure to COFs caused direct or indirect damages to the follicle structure in the ovaries, ovarian tissues were observed under TEM. Exposure to COFs resulted in follicular cell damage and apoptosis in ovaries, while no pathological abnormality was observed in the control rats (Fig. 2), indicating that COFs can affect follicular structure.

\section{The mRNA levels of GPR30, EGFR, STAT3, and ERK}

To investigate whether the signal pathway changes in endocrine disruption are involved in COF-induced apoptosis and inhibition of follicular growth, the expression levels of GPR30, EGFR, STAT3, and ERK mRNA were measured in ovarian tissue from rats with or without exposure to COFs (Fig. 3). The results showed that GPR30, EGFR, STAT3, and ERK mRNA were expressed in each group. There were statistically significant differences in the mRNA expression levels of GPR30, EGFR, STAT3, and ERK in each group $(F=18.861, p<0.01 ; F=14.040, p<0.01 ; F=35.431$, $p<0.01$; and $F=30.599, p<0.01$ ). The mRNA expression levels of GPR30 and EGFR decreased significantly in the high- and very-high-dose group $(p<0.01)$. The expression levels of STAT3 mRNA in the ovaries of rats treated with COFs (low dose, moderate dose, high dose, and very high dose) were significantly higher than that of the control rats, and the expression level of ERK mRNA increased significantly in the ovaries of rats treated with COFs (moderate dose, high dose, and very high dose) $(p<0.01)$.

\section{Discussion}

The present in vivo study found that COF exposure decreased the overall weight, including that of the ovaries, interrupted follicle development, hormone-level disorder, and increased the STAT3 and ERK mRNA levels in the ovaries at the estrous stage in female rats. However, the GRP30 and EGRF mRNA levels fluctuated with the COF dose at this stage.

\section{Exposure levels}

During the subchronic exposure experiment, the COF concentration was constant at $32.21 \pm 5.11 \mathrm{mg} / \mathrm{m}^{3}$. This observation was similar to that of $\mathrm{Wu}$ et al. in which the $\mathrm{COF}$ concentration was reported to be $25.1 \pm 2.3 \mathrm{mg} / \mathrm{m}^{3}$, with lard heated at $250 \pm 10{ }^{\circ} \mathrm{C}$ for $30 \mathrm{~min}$ in an iron pot (Wu et al. 1999). The COF concentration in our study was comparable to that of pan-fried beef in the western kitchen model $\left(19.5 \mathrm{mg} / \mathrm{m}^{3}\right.$ and $42.8 \mathrm{mg} / \mathrm{m}^{3} \mathrm{COFs}$ generated using an electric hob or a gas hob, respectively) (Svedahl et al. 2009). However, the COF concentration in our study was much higher than those from 19 restaurants in Norway (the highest was $6.6 \mathrm{mg} / \mathrm{m}^{3}$ in a small local restaurant, and the arithmetic mean for COF concentration for all of the kitchens was $0.62 \mathrm{mg} / \mathrm{m}^{3}$ ) (Svendsen et al. 2002). The chemical compositions of COFs are complicated and differ according to the oil type, food type, cooking method, and heating temperature used. Under the experimental conditions, we observed that aldehydes and alkyls were the main components in the COFs, and this observation was similar to the observations of a previous study (He et al. 2013). Furthermore, BaP was detected at a high concentration under the experimental conditions. Because the cooking duration is not more than $4 \mathrm{~h}$ 
in a typical family, the highest exposure time was set at $4 \mathrm{~h} /$ day. The experiment was performed for 56 days, so that the subchronic health effects of COF exposure on gonads could be observed in the female rats.

\section{COF exposure and the estrous cycle}

The estrous cycle is generally assessed according to changes in the vaginal epithelial cell structure to document the effects on reproductive cycles and provide an index of the functional status of the hypothalamic-pituitary-ovarian axis (Goldman et al. 2007). In our study, the rats in the control group had normal estrous cycles, which have been reported previously. However, we observed that the extension of the estrous cycle was associated with the COF exposure levels in a dose-dependent manner. Although only the metaestrous stage was significantly extended in the high- and very-highdose groups, it seemed that the cycle extension was mainly caused by the extension of the diestrous, metaestrous, and estrous stages, as indicated in Table 3. This effect was possibly caused by the $\mathrm{BaP}$ chemicals of COFs. BaP exposure extended the length of the estrous cycle by approximately $24 \mathrm{~h}$ among rats exposed to $\mathrm{BaP}$ at $100 \mu \mathrm{g} / \mathrm{m}^{3}$ (Archibong et al. 2012). This observation indicated an imbalance in the ovarian steroids imposed by $\mathrm{BaP}$. Consequently, irregular changes in the length of the estrous cycle occurred at the proestrous stage of the estrous cycle, in which estrogen is maximally secreted by the ovarian follicles (Archibong et al. 2012). A significant decrease in $E_{2}$ levels was observed at the proestrous stage among BaP-exposed rats. In our study, the $\mathrm{E}_{2}$ levels decreased in the very-high-dose group. Consequently, it was hypothesized that the extension of the estrous cycle duration in the COF-exposed rats was caused by the reduction in the level of circulating $E_{2}$, which is required to trigger the onset of the estrous stage in a timely manner, and the delay in attaining the serum $\mathrm{E}_{2}$ peak (Goldman et al. 2007).

\section{COF exposure and sex hormones}

The levels of four hormones, including follicle-stimulating hormone $(\mathrm{FSH})$, luteinizing hormone $(\mathrm{LH})$, estrogen $\left(\mathrm{E}_{2}\right)$, and progestin $\left(\mathrm{P}_{4}\right)$, are considered as an important evaluation index of the influence of foreign factors on the estrous cycle and follicle development. The secretion of reproductive hormones $\left(\mathrm{P}_{4}\right.$ and $\left.\mathrm{E}_{2}\right)$ from the ovaries is regulated by the release of LH and FSH from the anterior pituitary gland. Physiologically, increased $\mathrm{P}_{4}$ and $\mathrm{E}_{2}$ levels lead to decreased FSH and LH release via a negative feedback mechanism on the hypothalamic-anterior-pituitary axis. However, this typical feedback signaling was not observed in all time variance and exposure groups, which was possibly related to the endocrine disruption effects of the COFs. We observed that
LH levels increased in the high-dose and very-high-dose group, whereas $\mathrm{E}_{2}$ levels decreased in the high-dose and very-high-dose group. $\mathrm{P}_{4}$ in the high-dose group decreased significantly compared to the control group. This was possibly because $\mathrm{COF}$ exposure interrupted the hormonal patterns of the rats, as some studies have suggested (Archibong et al. 2012; McLean et al. 1977). Serum concentrations of $E_{2}$ and $\mathrm{LH}$, for example, decreased at the proestrous stage in BaPexposed rats, whereas those of $\mathrm{P}_{4}$ decreased at the diestrus I stage (Archibong et al. 2012). The increase in the concentrations of LH observed at the proestrous stage in the control rats free of $\mathrm{BaP}$ exposure suggested that a surge in this gonadotropin was imminent (Archibong et al. 2012). BaP delays the surge of LH that is normally observed throughout the proestrous stage. However, the LH surge may have occurred much later in the BaP-exposed rats at the proestrous stage, because these rats ovulated, albeit producing fewer eggs compared with the unexposed control rats (Archibong et al. 2012; McLean et al. 1977).

In the present study, $\mathrm{E}_{2}$ and $\mathrm{P}_{4}$ levels decreased, while $\mathrm{LH}$ levels increased in the high-dose and very-high-dose group. The results indicated that high-dose exposure to COFs may inhibit the secretion of $\mathrm{P}_{4}$ and $\mathrm{E}_{2}$ in the ovaries, and stimulate secretion of LH in the pituitaries through negative feedback. In addition, LH turned the granular cells into luteal cells such that they secreted pregnendione, leading to increased $\mathrm{P}_{4}$ levels. The results seemed that the sex hormones in COFs-exposed rats appeared in a pattern different from the normal one.

\section{COF exposure and body weight, uterus, and ovaries}

The results indicated that COF exposure increased the body weight compared with normal conditions. The curve of the increased body weights was consistent with that of the changes in the serum $E_{2}$ levels. Specifically, $E_{2}$ reached high levels in the low-dose group, and decreased slightly in the high- and very-high-dose groups. Conversely, the curve of body-weight gain varied with that of the serum LH levels. Estrogen promotes the accumulation of subcutaneous fat (Brown and Clegg 2010). Therefore, the body weight increased. By contrast, the anorexigenic effects of estradiol in adult female rats reduced their food intake during the estrus stage and led to a subsequent decrease in weight gain in the very-high-dose group (Eckel 2011).

The ovaries are a crucial target organ of many reproductive toxicants. A significant increase in the absolute weight of the fresh ovaries was observed in the rats in the lowand moderate-dose groups. However, a high-dose and very high-dose of COF exposure reduced the weight of the ovaries, although the difference was not significant; it suggests that high dose of COF is a direct cause of ovarian toxicity. The effects of COFs on the ovaries were exerted in a 
dose-dependent manner. Very high levels of COF exposure caused direct toxicity and reduced the ovary weight, and disturbed the development and functioning of the ovaries at the estrous stage. However, the uterus may be less sensitive to $\mathrm{COF}$ exposure than the ovaries, because no significant weight change in the rat uterus was observed in this study.

\section{COF exposure and the follicle types and ultrastructure}

Enumerating ovarian follicles is an efficient technique for estimating the extent of ovarian toxicity in female rats. Follicle development is regulated by sex hormones. Generally, increased $\mathrm{FSH}$ and $\mathrm{E}_{2}$ levels improve follicle development and maturity in the estrus period of rats. However, COFs may disrupt this process and affect their regulation. Our present study showed that follicle development in the highdose COFs was influenced. The ratio of secondary follicles decreased in the very high-dose group, possibly because their development was inhibited. However, follicle aging or maturation was accelerated in all dose groups.

The LH and FSH levels changed differentially throughout the ovulation cycles, with FSH being predominant in the early follicular phase and LH being predominant in the late follicular phase. Sequential FSH and LH predominance is crucial for appropriate follicular maturation, sex steroid production, and subsequent ovulation (McCartney 2010; Zhou et al. 2013). $E_{2}$ modulates steroidogenesis, promotes granulosa cell proliferation, and regulates follicular development. The surge in LH concentration in mammals is a functional endocrine event, initiating the stages of follicular and oocyte maturation that culminate in the release of an ovum or multiple ova. The asynchrony between the developing follicles and preovulatory LH surge can be induced by COF exposure, which can disturb follicle development. Therefore, we observed ovarian structures using H\&E staining and transmission electron microscopy to understand whether follicles in different stages had been destroyed. The morphological results showed that the numbers of follicle types were disrupted and that the structures were damaged by high-dose COF exposure, e.g., mitochondria were swollen and even vacuolated. The chromatin aggregation and more apoptotic bodies were present. Such as $\mathrm{BaP}$ was reported to reduce the secretory functions of the ovaries to interrupt the development of oocytes and cause atrophy of the ovaries (Archibong et al. 2012).

Ovarian follicular degeneration or atresia is a hormonally controlled apoptotic process (Kaipia and Hsueh 1997). The ultrastructural changes of ovarian cells in this experiment include swelling and edema of mitochondria, and the increase of lipid droplets and apoptotic bodies. Follicle atresia is mainly caused by the apoptosis of granulosa cells (GC). GC is an important cell for the synthesis and secretion of $\mathrm{E}_{2}$ hormone. The apoptosis and damage of granulosa cells will lead to the decrease of $E_{2}$ hormone secretion. Steroid hormones are mainly produced in mitochondria, which are closely related to lipid droplets in cytoplasm. Lipid droplets may help to store the substrates of steroid hormones and transport them to mitochondria. A large number of lipid droplets and mitochondria damage were found in the highdose group, suggesting that COFs may damage the ovary by impairing the synthesis and transport of steroid hormones. Therefore, morphological changes in these cells can disrupt ovarian secretion, leading to abnormal follicular development and atresia, and the corresponding estrus cycle also changed, which is consistent with the results of this study.

\section{COF exposure and the mRNA levels of GPR30, EGFR, STAT3, and ERK}

GPR30 is highly expressed in the granulosa cells and theca cells of ovaries, GPR30 may be involved in the rapid non-genomic effect of estrogen and genomic transcription reaction, and play an important role in cell proliferation and apoptosis. GPR30 binds to estrogen, and then rapidly activates adenylyl cyclase and mitogen-activated protein kinases, such as ERK, resulting in the mobilization of the intracellular $\mathrm{Ca}^{2+}$ concentration in cells (Giuliano et al. 2013). GPR-mediated transactivation of EGFR by estrogen provides a cross-talk mechanism between estrogen and serum growth factors; that is, it induces the EGF-like effects of estrogen (Filardo 2002). STAT3 is a transcription factor activated by various cytokines and growth factors, including interferons and EGF, and regulates the genes involved in cell growth and division, cell proliferation, and apoptosis (Klampfer 2006).

Studies have shown that many environmental estrogens, which can be combined with estrogen receptor (ER $\alpha$ and ER $\beta$ ), can be combined with estrogen $G$ protein-coupled receptor (GPR30), such as bisphenol A (8-50 times), nonylphenol and open fluffy (3-4 times), and iris flavone glycosides. The affinity with GPR30 is higher than that of $\mathrm{ER} \alpha$ and ER $\beta$. The combination of GPR30 is mainly produced by the estrogen effect (O'Dowd et al. 1998; Chen and Wang 2012). It has been reported that methylbenzene, phenol, alkyl, and phthalate esters in COFs are toxic to female gonads. In our study, we observed that COF exposure significantly decreased the $\mathrm{E}_{2}$ hormone level, GPR30, and EGFR expression levels of the rats in the high- and veryhigh-dose groups. GPR30 and EGFR were positively correlated with $\mathrm{E}_{2}$ and corpus luteum ratios in the female rats at the estrous stage. $E_{2}$, acting through $E R \alpha$, GPR30, or both, was reported to activate the rapid EGFR/ERK/c-Jun pathway in rat pachytene spermatocytes (Chimento et al. 2010). Therefore, GPR30 might be involved in mediating the effect of COFs on $\mathrm{E}_{2}$ hormone level. 
COF exposure increased STAT3 and ERK mRNA expression and LH levels in a dose-dependent manner, while the ratio of the corpus luteum decreased significantly. Furthermore, STAT3 and ERK were positively correlated with the ratios of the atretic follicles. The results indicated that $\mathrm{COF}$ exposure at any level possibly accelerated the aging of the follicle via the STAT3 and ERK signaling pathways.

\section{Conclusions}

Subchronic exposure to COFs could disrupt the estrous cycle, sex hormone patterns, and follicle development in female rats, mainly by disturbing the function of the hypothalamic-pituitary-ovarian axis. The study explored the role of the GPR30-mediated signaling pathway in the adverse effects of COFs on the female gonads. We found that COFs interrupted the mRNA expression levels of the related molecular signals, and led to hormonal disorders, abnormal cell proliferation and ovarian injury in rats. The findings of this study are of value in understanding the mechanism of the health effects of COFs in humans. The results suggest that experimental studies for determining the health effects of COFs in vitro and epidemiologic studies may be necessary.

Acknowledgements This study was funded by the Bureau of Science and Technology of Fuzhou City, Fujian Province, PR China (2009-S90; 2018-S-wt6) and Natural Science Foundation of Fujian Province (2016J01418), PR China.

\section{Compliance with ethical standards}

Conflict of interest No potential conflict of interest was reported by the authors.

Open Access This article is distributed under the terms of the Creative Commons Attribution 4.0 International License (http://creativeco mmons.org/licenses/by/4.0/), which permits unrestricted use, distribution, and reproduction in any medium, provided you give appropriate credit to the original author(s) and the source, provide a link to the Creative Commons license, and indicate if changes were made.

\section{References}

Archibong AE, Ramesh A, Inyang F, Niaz MS, Hood DB, Kopsombut $\mathrm{P}$ (2012) Endocrine disruptive actions of inhaled benzo(a) pyrene on ovarian function and fetal survival in fisher F-344 adult rats. Reprod Toxicol 34(4):635-643. https://doi.org/10.1016/j.reprotox.2012.09.003

Brown LM, Clegg DJ (2010) Central effects of estradiol in the regulation of food intake, body weight, and adiposity. J Steroid Biochem Mol Biol 122(1-3):65-73. https://doi.org/10.1016/j.jsbmb 2009.12.005
Chen S, Wang T (2012) New estrogen receptor GPR30/GPER1 and its role in breast cancer. Adv Physiol 43(1):75-80

Chimento A, Sirianni R, Delalande C, Silandre D, Bois C, Andò S, Maggiolini M, Carreau S, Pezzi V (2010) 17 beta-estradiol activates rapid signaling pathways involved in rat pachytene spermatocytes apoptosis through GPR30 and ER alpha. Mol Cell Endocrinol 320(1-2):136-144. https://doi.org/10.1016/j. mce.2010.01.035

Eckel LA (2011) The ovarian hormone estradiol plays a crucial role in the control of food intake in females. Physiol Behav 104(4):517524. https://doi.org/10.1016/j.physbeh.2011.04.014

Filardo EJ (2002) Epidermal growth factor receptor (EGFR) transactivation by estrogen via the G-protein-coupled receptor, GPR30: a novel signaling pathway with potential significance for breast cancer. J Steroid Biochem Mol Biol 80(2):231-238

Filippi S, Vignozzi L, Morelli A, Chavalmane AK, Sarchielli E, Fibbi B, Saad F et al (2009) Testosterone partially ameliorates metabolic profile and erectile responsiveness to PDE5 inhibitors in an animal model of male metabolic syndrome. J Sex Med 6(12):3274-3288. https://doi.org/10.1111/j.1743-6109.2009.01467.x

Giuliano M, Trivedi MV, Schiff R (2013) Bidirectional crosstalk between the estrogen receptor and human epidermal growth factor receptor 2 signaling pathways in breast cancer: molecular basis and clinical implications. Breast Care 8(4):256-262. https://doi. org/10.1159/000354253

Goldman JM, Murr AS, Cooper RL (2007) The rodent estrous cycle: characterization of vaginal cytology and its utility in toxicological studies. Birth Defects Res Part B Dev Reprod Toxicol 80(2):8497. https://doi.org/10.1002/Bdrb.20106

He WQ, Nie L, Tian G, Li J, Shao X, Wang MY (2013) Study on the chemical compositions of VOCs emitted by cooking oils based on GC-MS. Huan Jing Ke Xue 34(12):4605-4611

Huang Y, Ho SS, Ho KF, Lee SC, Yu JZ, Louie PK (2011) Characteristics and health impacts of VOCs and carbonyls associated with residential cooking activities in Hong Kong. J Hazard Mater 186(1):344-351. https://doi.org/10.1016/j.jhazmat.2010.11.003

Juliani CC, Silva-Zacarin EC, Santos DC, Boer PA (2008) Effects of atrazine on female Wistar rats: morphological alterations in ovarian follicles and immunocytochemical labeling of $90 \mathrm{kDa}$ heat shock protein. Micron 39(5):607-616. https://doi.org/10.1016/j. micron.2007.04.006

Kaipia A, Hsueh AJW (1997) Regulation of ovarian follicle atresia. Annu Rev Physiol 59:349-363. https://doi.org/10.1146/annur ev.physiol.59.1.349

Kang K, Lee SB, Jung SH, Cha KH, Park WD, Sohn YC, Nho CW (2009) Tectoridin, a poor ligand of estrogen receptor alpha, exerts its estrogenic effects via an ERK-dependent pathway. Mol Cells 27(3):351-357. https://doi.org/10.1007/s10059-009-0045-8

Kawai T, Mihara T, Kawashima I, Fujita Y, Ikeda C, Negishi H, Shimada M (2012) Endogenous acetaldehyde toxicity during antral follicular development in the mouse ovary. Reprod Toxicol 33(3):322-330. https://doi.org/10.1016/j.reprotox.2012.01.001

Ke Y, Cheng J, Zhang Z, Zhang R, Zhang Z, Shuai Z, Wu T (2009) Increased levels of oxidative DNA damage attributable to cooking-oil fumes exposure among cooks. Inhal Toxicol 21(8 11):682-687. https://doi.org/10.1080/08958370802474728

Klampfer L (2006) Signal transducers and activators of transcription (STATs): novel targets of chemopreventive and chemotherapeutic drugs. Curr Cancer Drug Targets 6(2):107-121. https://doi. org/10.2174/156800906776056491

Kong G, Zhang J, Zhang S, Shan C, Ye L, Zhang X (2011) Upregulated MicroRNA-29a by hepatitis B virus X protein enhances hepatoma cell migration by targeting PTEN in cell culture model. PLoS One 6(5):e19518. https://doi.org/10.1371/journal.pone.0019518

Lee T, Gany F (2013) Cooking oil fumes and lung cancer: a review of the literature in the context of the U.S. population. J Immigr 
Minor Health 15(3):646-652. https://doi.org/10.1007/s1090 3-012-9651-1

Luo LL, Huang J, Fu YC, Xu JJ, Qian YS (2008) Effects of tea polyphenols on ovarian development in rats. J Endocrinol Investig 31(12):1110-1118

McCartney CR (2010) Maturation of sleep-wake gonadotrophinreleasing hormone secretion across puberty in girls: potential mechanisms and relevance to the pathogenesis of polycystic ovary syndrome. J Neuroendocrinol 22(7):701-709. https://doi.org/10.1 111/j.1365-2826.2010.02029.x

McLean BK, Rubel A, Nikitovitch-Winer MB (1977) Differential effects of exposure to tobacco-smoke on secretion of luteinizing-hormone and prolactin in proestrous rat. Endocrinology 100(6):1566-1570

O’Dowd BF, Nguyen T, Marchese A, Cheng R, Lynch KR, Heng HH, Kolakowski LF Jr, George SR (1998) Discovery of three novel G-protein-coupled receptor genes. Genomics 47(2):310-313

Prossnitz ER, Barton M (2014) Estrogen biology: new insights into GPER function and clinical opportunities. Mol Cell Endocrinol 389(1-2):71-83. https://doi.org/10.1016/j.mce.2014.02.002

Svedahl S, Svendsen K, Qvenild T, Sjaastad AK, Hilt B (2009) Short term exposure to cooking fumes and pulmonary function. J Occup Med Toxicol 4:9. https://doi.org/10.1186/1745-6673-4-9

Svendsen K, Jensen HN, Sivertsen I, Sjaastad AK (2002) Exposure to cooking fumes in restaurant kitchens in Norway. Ann Occup Hyg 46(4):395-400. https://doi.org/10.1093/annhyg/mef045

Thomas P, Dong J (2006) Binding and activation of the seven-transmembrane estrogen receptor GPR30 by environmental estrogens: a potential novel mechanism of endocrine disruption. J Steroid Biochem Mol Biol 102(1-5):175-179

USEPA (2009) Compendium Method TO-17. http://www.epa.gov/ttn/ amtic/files/ambient/airtox/to-17r.pdf. Accessed 07 Feb 2015
Vermi W, Giurisato E, Lonardi S, Balzarini P, Rossi E, Medicina D, Bosisio D et al (2013) Ligand-dependent activation of EGFR in follicular dendritic cells sarcoma is sustained by local production of cognate ligands. Clin Cancer Res 19(18):5027-5038. https:// doi.org/10.1158/1078-0432.Ccr-13-1275

Wang HX, Wang XY, Zhou DX, Zheng LR, Zhang J, Huo YW, Tian H (2013) Effects of low-dose, long-term formaldehyde exposure on the structure and functions of the ovary in rats. Toxicol Ind Health 29(7):609-615. https://doi.org/10.1177/0748233711430983

Wu PF, Chiang TA, Ko YC, Lee H (1999) Genotoxicity of fumes from heated cooking oils produced in Taiwan. Environ Res 80(2 Pt 1):122-126. https://doi.org/10.1006/enrs.1997.3798

Youqiong X, Yu ITS, Jie L, Wei Z, Hua K, Guoxing C (2012) Analysis of cooking oil fumes from different cooking oils and cooking methods. Chin J Hyg Insp 22(10):2271-2274

Zhang L, Hou D, Chen X, Li D, Zhu L, Zhang Y, Li J et al (2012) Exogenous plant MIR168a specifically targets mammalian LDLRAP1: evidence of cross-kingdom regulation by microRNA. Cell Res 22(1):107-126. https://doi.org/10.1038/cr.2011.158

Zhou Y, Zhang H, He J, Chen X, Ding Y, Wang Y, Liu X (2013) Effects of sodium fluoride on reproductive function in female rats. Food Chem Toxicol 56:297-303. https://doi.org/10.1016/j. fct.2013.02.026

Zhu X, Wang K, Zhu J, Koga M (2001) Analysis of cooking oil fumes by ultraviolet spectrometry and gas chromatography-mass spectrometry. J Agric Food Chem 49(10):4790-4794. https://doi. org/10.1021/Jf001084y

Publisher's Note Springer Nature remains neutral with regard to jurisdictional claims in published maps and institutional affiliations. 